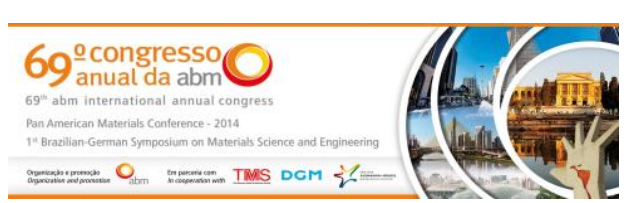

Tema: Metalurgia física e comportamento de materiais em temperaturas elevadas

\title{
SIMULAÇÃO DA LAMINAÇÃO VIA STECKEL DE UM AÇO MICROLIGADO AO NIÓBIO UTILIZANDO ENSAIOS DE TORÇÃO*
}

\author{
Nilo Nogueira da Silva \\ Nilton José Lucinda de Oliveira² \\ Thompson Junior Avila Reis ${ }^{3}$ \\ Margareth Spangler Andrade 4
}

\section{Resumo}

O objetivo deste trabalho foi investigar os efeitos da temperatura de laminação na microestrutura de um aço microligado ao Nióbio através de simulação por ensaios de torção a quente. Ensaios foram realizados com deformações em resfriamento contínuo para determinar as temperaturas de não recristalização da austenita (Tnr) e de início da transformação austenita-ferrita (Ar3). Foram realizados ensaios de torção simulando diferentes esquemas de laminação a quente em laminador Steckel, variando-se as temperaturas dos passes de acabamento. Foi observado, nas curvas tensão em função da deformação dos ensaios de torção, gradual encruamento da austenita quando a temperatura da última deformação foi inferior à $870^{\circ} \mathrm{C}$. Foi também observado que o tamanho de grão ferrítico cresce com temperatura de laminação de acabamento.

Palavras-chave: Aço microligado; Laminador Steckel; Ensaios de torção; Simulação de laminação; $\mathrm{Nb}$.

\section{STECKEL MILL HOT ROLLING SIMULATION BY TORSION TEST OF A NIOBIUM MICROALLOYED STEEL}

\section{Abstract}

The objective was to investigate the effect of hot rolling temperature on the microstructure of Niobium microalloyed steel by torsion test simulation. Torsion tests were carried out using deformations in continuous cooling to obtain austenite non recrystallization (Tnr) and austenite - ferrite transformation (Ar3) temperatures. Torsion tests were also conducted to simulate Steckel mill hot rolling schemes by varying the temperature of the finishing rolling passes. The torsion stress-strain curves showed gradual austenite strain hardening for last deformation temperature below $870{ }^{\circ} \mathrm{C}$. It was also observed that the ferritic grain size increases with finishing rolling temperature.

Keywords: Microalloyed steel; Steckel mill; Torsion test; Hot rolling simulation; Nb.

1 Físico, Mestrando da Redemat, UFOP, Instituto Senai de Inovação em Metalurgia e Ligas Especiais, Belo Horizonte, MG, Brasil.

2 Engenheiro Metalúrgico, MSc. Pesquisador em Tecnologia, Instituto Senai de Inovação em Metalurgia e Ligas Especiais, Belo Horizonte, MG, Brasil.

3 Engenheiro da Computação, MSc. Pesquisador em Tecnologia, Instituto Senai de Inovação em Metalurgia e Ligas Especiais, Belo Horizonte, MG, Brasil.

4 Física, Dra . Pesquisadora em Tecnologia, Instituto Senai de Inovação em Metalurgia e Ligas Especiais, Belo Horizonte, MG, Brasil.

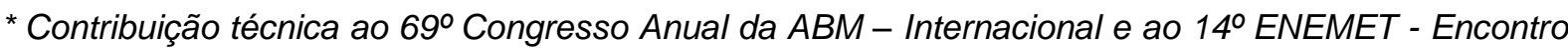
Nacional de Estudantes de Engenharia Metalúrgica, de Materiais e de Minas, 21 a 25 de julho de 2014, São Paulo, SP, Brasil.
} 


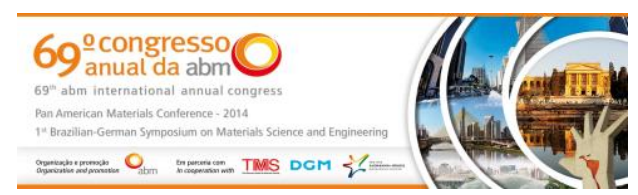

\section{INTRODUÇÃO}

Os aços de alta resistência e baixa liga (ARBL) têm sido amplamente utilizados em vários setores industriais como o automobilístico e o de estruturas, incentivando estudos direcionados à melhoria da resistência deste material. São conhecidos por terem sua resistência aumentada pela combinação de refinamento de grão, endurecimento por solução sólida e por precipitação. As principais pesquisas se concentram no refinamento de grão, utilizando adições de elementos microligantes, combinado com o controle de processamento termomecânico [1].

Nestes aços os elementos microligantes promovem diferentes efeitos sobre a microestrutura. $\mathrm{O} \mathrm{Nb}$ tem sido o mais efetivo para obter as propriedades desejadas quando combinado com tratamento termomecânico [2]. Este elemento apresenta uma solubilidade intermediária e forte influência sobre a cinética de recristalização da austenita durante a laminação a quente, que resulta no refino de grão ferrítico após a transformação austenita-ferrita [3,4].

Um dos métodos de laminação destes aços é através da utilização de um laminador tipo Steckel. Por ser reversível, o processo de laminação de acabamento neste laminador apresenta uma cinética diferente dos laminadores convencionais que possuem várias cadeiras de acabamento montadas em sequencia [5].

Basicamente, o tratamento termomecânico realizado durante o processo de laminação controlada pode ser dividido em três regiões:

Região 1 - Ocorre a altas temperaturas, ou seja, a austenita que está sendo deformada é recristalizada promovendo um refinamento dos seus grãos;

Região 2 - Em temperaturas intermediárias, a deformação da austenita é realizada sem que ocorra a recristalização, deste modo o material apresenta mudança de morfologia dos grãos e acúmulo de encruamento residual, fazendo com que o número de sítios disponíveis para nucleação posterior da ferrita seja multiplicado e o seu crescimento restringido.

Região 3 - Ocorre abaixo da Ar3, onde existem as duas fases austenita e ferrita. Neste processo de deformação, a ferrita sofre encruamento que ocasiona o aumento da resistência do material. A austenita ao sofrer encruamento aumenta o número de sítios disponíveis para nucleação da ferrita, fazendo com que a ferrita transformada neste estágio possua grão ainda mais fino que o produzido na região 2.

Deve ser destacada a importância de estudar os fenômenos metalúrgicos que ocorrem durante o processo de laminação a quente dos aços nas temperaturas críticas (Tnr, Ar3 e Ar1), pois acontecem alterações relevantes na microestrutura além das transformações de fases. Com o conhecimento destas temperaturas e seus efeitos é possível ajustar os parâmetros de processamento como: temperatura, taxa de deformação, deformação, taxa de resfriamento e tempo entre passes, com o objetivo de melhorar as propriedades mecânicas do material.

A temperatura de não recristalização (Tnr) separa a região 1 da região 2 e a temperatura de transformação austenita-ferrita (Ar3) separa a região 2 da região 3.

Tnr e Ar3 podem ser calculadas a partir da composição química dos aços, conforme equações 1 [6] e 2 [7] que foram estabelecidas a partir de correlações múltiplas de resultados experimentais.

$$
\begin{aligned}
& T n r=887+464 C+(6445 N b-644 \sqrt{N b})+(732 V-230 \sqrt{V})+890 T i+363 A l- \\
& 357 S i
\end{aligned}
$$

* Contribuição técnica ao 69 Congresso Anual da ABM - Internacional e ao 14ํㅡㄹ ENEMET - Encontro Nacional de Estudantes de Engenharia Metalúrgica, de Materiais e de Minas, 21 a 25 de julho de 2014, São Paulo, SP, Brasil. 


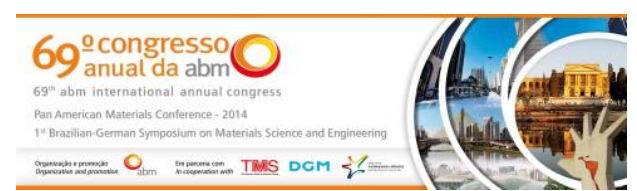

Onde t é a espessura em mm da placa laminada, considerando t entre 8 e $30 \mathrm{~mm}$. Uma técnica capaz de reproduzir as condições de processamento a quente é o ensaio de torção a quente, sendo que, com bom controle da temperatura e da taxa de deformação, é possível obter amostras com microestrutura similar às produzidas na laminação [8-10]. Neste tipo de ensaio é possível simular todo o processo de laminação desde o aquecimento inicial da placa até o bobinamento final da chapa [11]. Ainda, admite a realização de resfriamento rápido da amostra em qualquer estágio da deformação, tornado possível o acompanhamento das mudanças microestruturais que ocorrem em qualquer etapa de deformação [10]. Na simulação física dos processos de laminação a quente por meio da técnica de ensaios de torção, as condições de processamento industrial são reproduzidas graças a geometria do corpo de prova, a qual, por sua vez, possibilita a obtenção de grandes deformações acumuladas com controle de tempo e temperatura [11].

Nos ensaios de torção com múltipla deformação em resfriamento contínuo é possível determinar as temperaturas críticas de processamento, possibilitando a analise dos fenômenos metalúrgicos e dos efeitos das variações dessas temperaturas que ocorrem nos materiais em função dos parâmetros de processamento [12,13].

Neste trabalho, foi estudado um aço microligado ao Nióbio simulando sua laminação através da técnica de ensaios de torção a quente, levantando os possíveis ciclos térmicos e esquemas de deformação a serem utilizados em um laminador Steckel. Analise microestrutural foi realizada por microscopia ótica e ensaios de microdureza.

\section{MATERIAIS E MÉTODOS}

Neste trabalho foi utilizado um aço microligado ao Nióbio para aplicações estruturais, retirado de um esboço da laminação de perfil, fornecido pela Gerdau Ouro Branco, cuja composição química em \% em peso está indicada na Tabela 1.

Tabela 1. Composição química do aço microligado ao Nióbio (\% em peso)

\begin{tabular}{cccccccccc}
\hline $\mathrm{C}$ & $\mathrm{Mn}$ & $\mathrm{Si}$ & $\mathrm{P}$ & $\mathrm{S}$ & $\mathrm{Ti}$ & $\mathrm{Nb}$ & $\mathrm{V}$ & $\mathrm{Al}$ & $\mathrm{N}^{*}$ \\
\hline 0,15 & 1,10 & 0,2 & 0,02 & 0,025 & 0,001 & 0,022 & 0,004 & 0,002 & 53 \\
\hline
\end{tabular}

(*) Em ppm.

Corpos de provas com $7 \mathrm{~mm}$ de diâmetro por $15 \mathrm{~mm}$ de comprimento útil foram usinados paralelos à direção de laminação para a realização de ensaios de torção a quente.

Ensaios de torção a quente em atmosfera inerte foram realizados em duas condições distintas. O equipamento utilizado foi uma máquina de torção Instron adaptada para ensaios a quente com controle de ciclo térmico e de deformações. Primeiramente, foi realizado um ensaio com múltiplas deformações em resfriamento contínuo para determinação das temperaturas críticas de processamento do material (Tnr, Ar3 e Ar1), conforme metodologia descrita na literatura [11]. Também foram realizados os cálculos de Tnr e Ar3 utilizando as equações 1 e 2, respectivamente, para comparação com os valores obtidos no ensaio de torção à quente. Neste ensaio o corpo de prova é aquecido até a temperatura de $1200^{\circ} \mathrm{C}$, mantido nesta temperatura por dois minutos e, em seguida resfriado a uma taxa de $60^{\circ} \mathrm{C}$ por minuto. Durante o resfriamento, deformações de 0,2 são aplicadas em intervalos de 30 s a partir da temperatura de $1170^{\circ} \mathrm{C}$.

* Contribuição técnica ao $69^{\circ}$ Congresso Anual da ABM - Internacional e ao 14ํㅡㄹ ENEMET - Encontro Nacional de Estudantes de Engenharia Metalúrgica, de Materiais e de Minas, 21 a 25 de julho de 2014, São Paulo, SP, Brasil. 


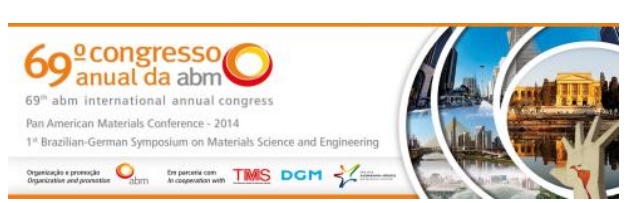

Em seguida, ensaios de torção foram utilizados para simulação da laminação industrial em um laminador do tipo Steckel. Nesta simulação foi considerado o procedimento de reaquecimento e os passes de desbaste e de acabamento aplicados na produção do aço. Nas Tabelas 2 e 3 estão detalhados os parâmetros de laminação que foram simulados. Os tempos entre passes foram calculados para o meio do comprimento da tira.

Tabela 2. Esquemas de passes para a simulação do aço no laminador Steckel equivalente à etapa de desbaste

\begin{tabular}{cccc}
\hline Passe & Deformação Equivalente & Tempo entre passes $(\mathrm{s})$ & Temperatura $\left({ }^{\circ} \mathrm{C}\right)$ \\
\hline R1 & 0,16 & 5 & 1200 \\
R2 & 0,24 & 5 & 1160 \\
R3 & 0,3 & 6 & 1130 \\
R4 & 0,37 & 6 & 1100 \\
R5 & 0,42 & 8 & 1070 \\
R6 & 0,44 & 10 & 1030 \\
R7 & 0,45 & 13 & 1000 \\
\hline
\end{tabular}

Tabela 3. Esquemas de passes para a simulação do aço no laminador Steckel equivalente à etapa de acabamento

\begin{tabular}{cccccccccc}
\hline \multirow{2}{*}{ Passe } & Deform. & Tempo & \multicolumn{7}{c}{ Temperatura $\left({ }^{\circ} \mathrm{C}\right)$} \\
\cline { 5 - 9 } & Equiv. & $\begin{array}{c}\text { entre } \\
\text { passes (s) }\end{array}$ & Ens. 1 & Ens. 2 & Ens. 3 & Ens. 4 & Ens. 5 & Ens. 6 & Ens. 7 \\
\hline F1 & 0,44 & $*$ & 960 & 930 & 900 & 870 & 840 & 810 & 780 \\
F2 & 0,41 & 11 & 960 & 930 & 900 & 870 & 840 & 810 & 780 \\
F3 & 0,38 & 10 & 960 & 930 & 900 & 870 & 840 & 810 & 780 \\
F4 & 0,33 & 14 & 950 & 920 & 890 & 860 & 830 & 800 & 770 \\
F5 & 0,28 & 20 & 940 & 910 & 880 & 850 & 820 & 790 & 760 \\
F6 & 0,21 & 30 & 930 & 900 & 870 & 840 & 810 & 780 & 750
\end{tabular}

$\left(^{*}\right) \mathrm{O}$ tempo entre passes da deformação de acabamento $\mathrm{F1}$ variou de acordo com a temperatura de realização dos ensaios.

Nestes ensaios foram variadas as temperaturas das seis últimas deformações aplicadas nos corpos de prova, correspondentes aos passes de acabamento do esquema de laminação no Steckel. As demais variáveis foram mantidas constantes, sendo que todos os corpos de prova foram igualmente aquecidos até a temperatura de $1230^{\circ} \mathrm{C}$ a uma taxa de $2^{\circ} \mathrm{C} / \mathrm{s}$ e mantidos nesta temperatura por 2 minutos. Em seguida foram resfriados a uma taxa compatível com o tempo entre passes e aplicadas sete deformações equivalentes à etapa de desbaste no laminador, conforme previsto na Tabela 2. Posteriormente, aplicaram-se as deformações equivalentes à etapa de acabamento. Cada ensaio teve esta etapa realizada a partir de uma temperatura específica, conforme discriminado na Tabela 3 . No final da ultima deformação os corpos de prova foram resfriados até a temperatura de $550^{\circ} \mathrm{C}$ para simular o resfriamento entre o laminador e a bobinadeira, sendo utilizada uma taxa de resfriamento de $5^{\circ} \mathrm{C} / \mathrm{s}$.

Os resultados destes ensaios foram relacionados com as análises metalográficas (tamanho de grão) e ensaios mecânicos (microdureza).

\footnotetext{
* Contribuição técnica ao 69ำ Congresso Anual da ABM - Internacional e ao 14ํㅡㄹ ENEMET - Encontro Nacional de Estudantes de Engenharia Metalúrgica, de Materiais e de Minas, 21 a 25 de julho de 2014, São Paulo, SP, Brasil.
} 


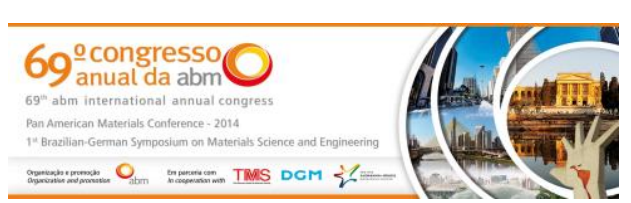

Para a análise microestrutural por microscopia óptica, os corpos de prova de torção foram cortados com discos abrasivos, sendo todo o comprimento útil embutido e 0 lixamento e polimento realizados a partir da superfície, em seção longitudinal ao eixo do corpo de prova. Após ataque com nital 5\%, foi determinado o tamanho de grão ferrítico e observada à morfologia destes em relação às temperaturas dos ensaios de torção. Para a determinação do tamanho de grão ferrítico das amostras foi utilizado o software Image-Pro, sendo o valor calculado pela média de no mínimo dez medidas.

Os ensaios de microdureza foram realizados em um microdurômetro de marca Future Tech, modelo FM-700, no padrão Vickers com carga de $300 \mathrm{~g}$ ( $\left.\mathrm{HV}_{300}\right)$ nas seções preparadas para a metalografia óptica. Os valores de microdureza foram relacionados com as temperaturas de último passe das simulações da laminação de acabamento e com os tamanhos de grão ferrítico obtidos.

\section{RESULTADOS E DISCUSSÃO}

\subsection{Ensaio com Múltiplas Deformações em Resfriamento Contínuo}

A Figura 3 ilustra graficamente (a) a tensão equivalente em função da deformação equivalente obtidos no ensaio em resfriamento contínuo e (b) a tensão equivalente média em função do inverso da temperatura absoluta.

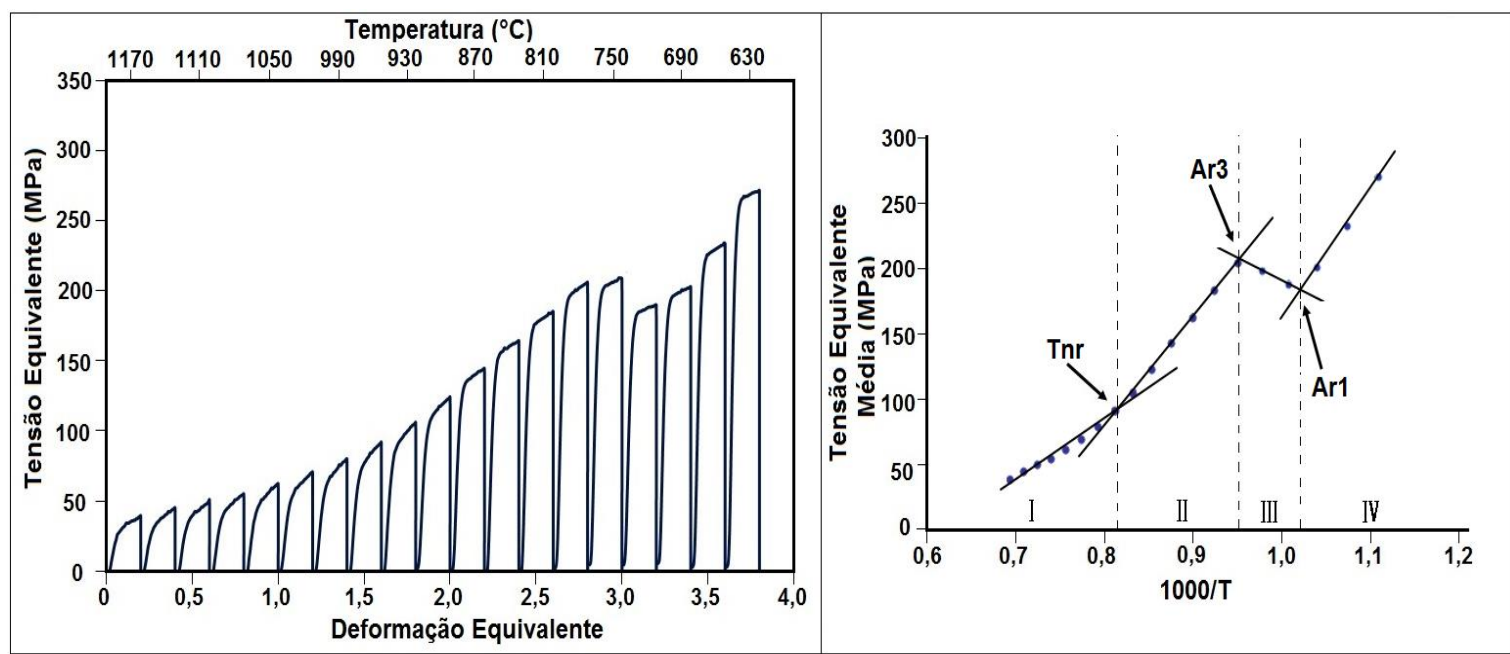

Figura 3. (a) Curva de tensão versus deformação obtida através do ensaio de torção com múltiplas deformações. (b) Gráfico da tensão média equivalente versus 1000x1/T, mostrando Tnr, Ar3 e Ar1 para o aço.

Na Figura 3(a) é possível observar a variação da tensão em relação à temperatura em que a deformação foi aplicada. Foi notado que a tensão aumenta quando a temperatura diminui, e que ocorre amaciamento entre passes (recristalização estática da austenita) acima de $960^{\circ} \mathrm{C}$. Já em temperaturas menores do que $960^{\circ} \mathrm{C}$ ocorre aumento acentuado da tensão, com acúmulo de encruamento na austenita. Este fato é decorrente da mudança da região de recristalização para a região de encruamento. Esta mudança de comportamento permite determinar Tnr.

Seguindo a diminuição de temperatura, observa-se a queda de tensão, evidenciando o aparecimento de ferrita, correspondente à temperatura de inicio de transformação

\footnotetext{
* Contribuição técnica ao $69^{\circ}$ Congresso Anual da ABM - Internacional e ao 14ํㅡㄹ ENEMET - Encontro Nacional de Estudantes de Engenharia Metalúrgica, de Materiais e de Minas, 21 a 25 de julho de 2014, São Paulo, SP, Brasil.
} 


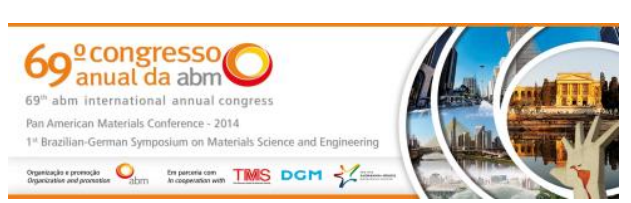

austenita-ferrita (Ar3). Finalmente, o aumento da tensão com a diminuição da temperatura evidencia o final da transformação austenítica ou Ar1.

Na Figura 3(b) é representado o gráfico de tensão média equivalente pelo inverso da temperatura absoluta vezes mil $(1000 \times 1 / T)$. Neste gráfico é possível determinar com mais precisão os valores de Tnr, Ar3 e Ar1. A temperatura de transição das regiões com diferentes taxas de aumento da tensão equivalente é a temperatura Tnr e a temperatura em que inicia diminuição da tensão equivalente indica Ar3. Estes dados são relacionados na Tabela 4 com os valores obtidos nos cálculos empregando as equações 1 e 2 citadas acima para Tnr e Ar3, respectivamente.

Tabela 4. Valores de Tnr, Ar3 e Ar1 obtidos no ensaio de torção e através do calculo utilizando as equações descritas na literatura

\begin{tabular}{cccc}
\hline & $\mathrm{Tnr}$ & $\mathrm{Ar3}$ & $\mathrm{Ar} 1$ \\
\hline Calculado & $925^{\circ} \mathrm{C}$ & $775^{\circ} \mathrm{C}$ & - \\
\hline Ensaio de Torção & $950^{\circ} \mathrm{C}$ & $780^{\circ} \mathrm{C}$ & $715^{\circ} \mathrm{C}$ \\
\hline
\end{tabular}

Foi observada boa relação entre os valores calculados e os obtidos através do ensaio de torção, apresentando uma diferença de aproximadamente $3 \%$ para Tnr e menos de $1 \%$ para Ar3. Resultados similares foram encontrados na literatura, onde foi estudado aço de composição química semelhante [14].

\subsection{Simulação da Laminação Industrial}

As curvas de tensão versus deformação obtidas nos ensaios para simulação de laminação estão apresentadas no gráfico da Figura 4.

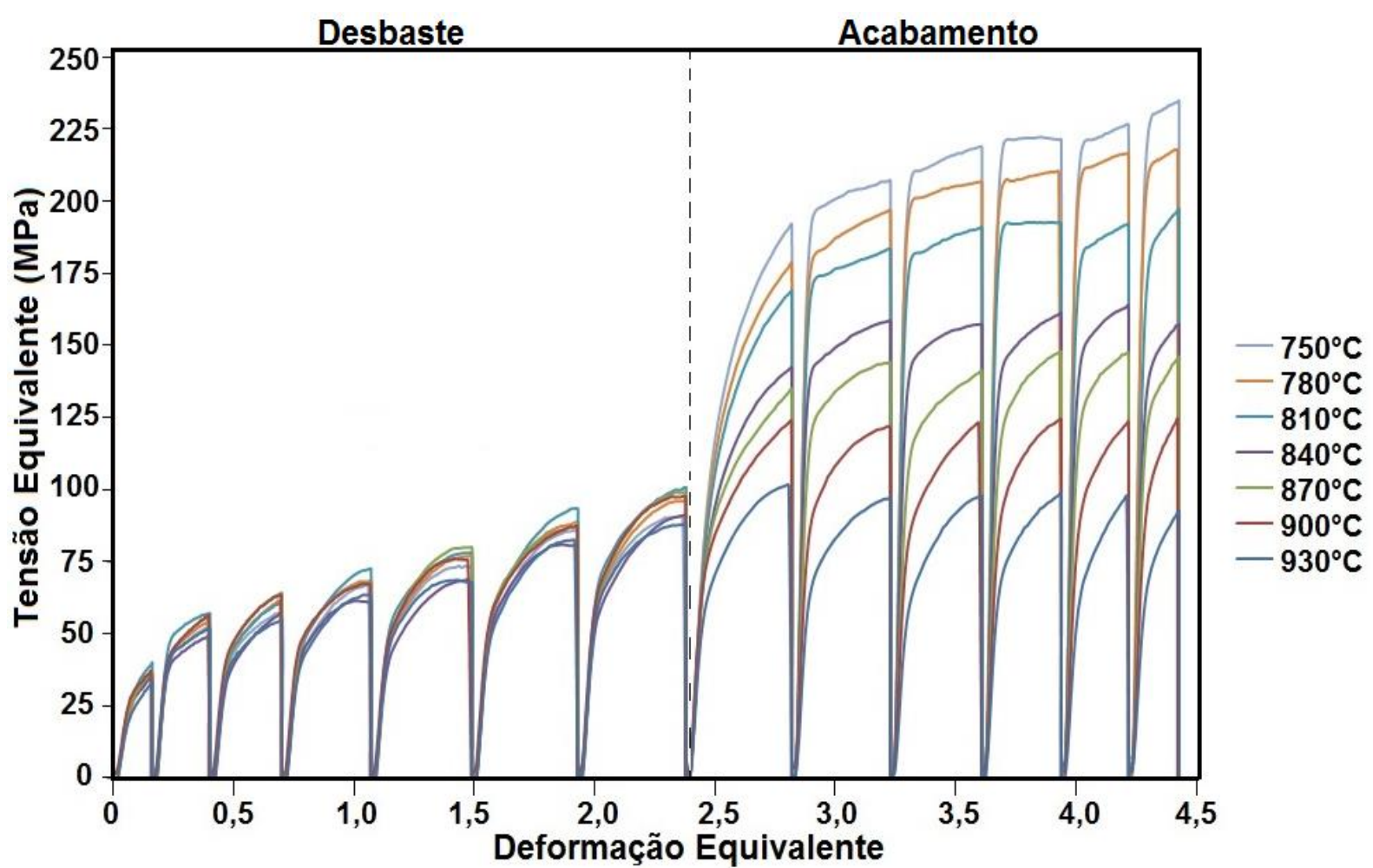

Figura 4. Curvas de tensão versus deformação geradas através dos ensaios de torção da simulação de laminação. Os sete primeiros passes representam o desbaste e os demais a laminação de acabamento. Temperaturas de último passe variando entre $930^{\circ} \mathrm{C}$ e $750^{\circ} \mathrm{C}$.

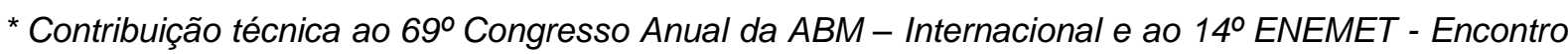
Nacional de Estudantes de Engenharia Metalúrgica, de Materiais e de Minas, 21 a 25 de julho de 2014, São Paulo, SP, Brasil. 
As sete primeiras deformações são equivalentes à etapa de desbaste e comuns a todos os ensaios. As temperaturas do último passe de acabamento das simulações são mostradas na legenda do gráfico, variando de $930^{\circ} \mathrm{C}$ a $750^{\circ} \mathrm{C}$.

Algumas observações podem ser feitas pela análise das curvas da Figura $4 . \mathrm{Na}$ região correspondente à laminação de desbaste, não foi observado amaciamento dinâmico em nenhuma das deformações, ocorrendo recristalização estática entre os passes evidenciada pelo fato das tensões de escoamento em cada passe serem menores que a tensão máxima do passe anterior. $O$ aumento de tensão de um passe para outro se deve apenas à queda de temperatura. Portanto, toda a laminação de desbaste ocorre na região de recristalização.

O mesmo comportamento, recristalização entre passes, foi observado para a laminação de acabamento nos ensaios com temperatura de última deformação entre 870 e $930^{\circ} \mathrm{C}$, apesar de serem temperaturas abaixo de Tnr. A recristalização em temperaturas abaixo da Tnr pode ter ocorrido devido às maiores deformações em cada passe que aquelas realizadas nos ensaios em resfriamento contínuo. Deve ser ainda observado o elevado tempo de espera entre o desbaste e o acabamento e a pequena queda de temperatura durante o acabamento.

$\mathrm{Na}$ região de laminação de acabamento, nos ensaios com temperatura de último passe abaixo de $870^{\circ} \mathrm{C}$, foi constatado o acúmulo de encruamento entre passes, ocasionalmente observando-se pequeno amaciamento entre passes. Já para o ensaio realizado com temperatura de último passe de $750^{\circ} \mathrm{C}$, abaixo de $\mathrm{Ar} 3$, foi observada recuperação dinâmica no quarto passe de acabamento, evidenciando a presença de ferrita na microestrutura.

\subsection{Microestrutura das Amostras Após Simulação de Laminação}

As imagens de microscopia óptica na Figura 5 permitem observar as características microestruturais da região deformada nos corpos de prova para seis temperaturas de último passe.

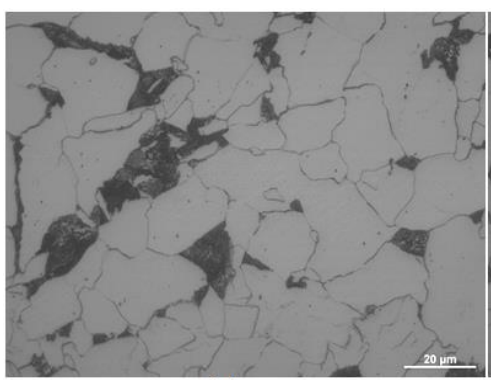

(a)

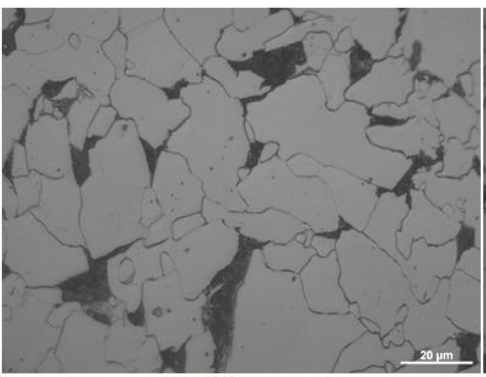

(b)

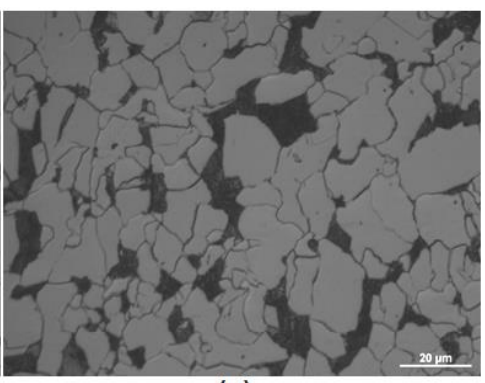

(c)

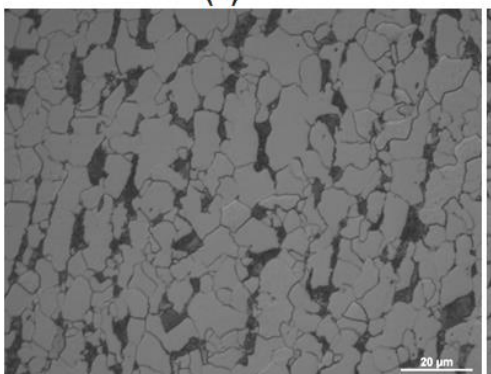

(d)

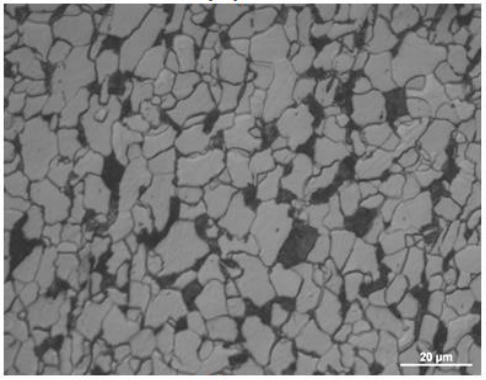

(e)

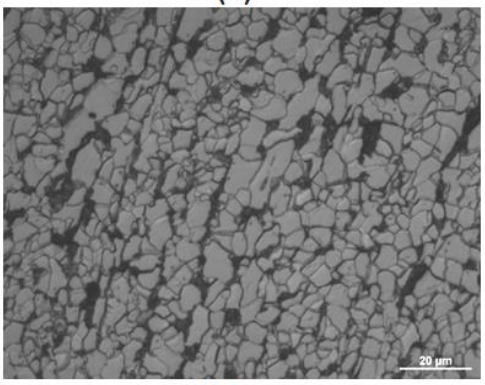

(f)

Figura 5. Imagens de microscopia óptica nas regiões deformadas dos corpos de prova de torção para as temperaturas de último passe de (a) $930^{\circ} \mathrm{C}$, (b) $870^{\circ} \mathrm{C}$, (c) $840^{\circ} \mathrm{C}$, (d) $810^{\circ} \mathrm{C}$, (e) $780^{\circ} \mathrm{C} \mathrm{e} \mathrm{(f)} 750^{\circ} \mathrm{C}$. Ataque químico nital.

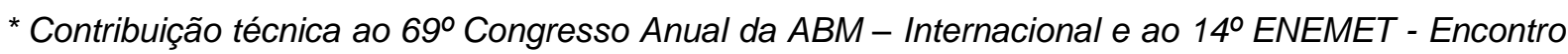
Nacional de Estudantes de Engenharia Metalúrgica, de Materiais e de Minas, 21 a 25 de julho de 2014, São Paulo, SP, Brasil. 


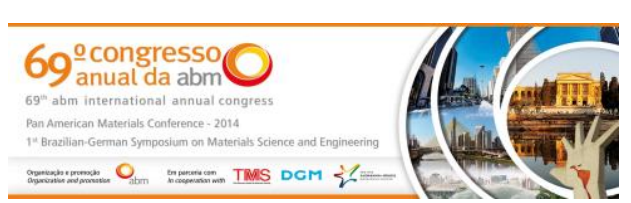

Estas características estão em acordo com as observações realizadas nas curvas de torção da Figura 4.

É possível constatar o refinamento do grão ferrítico à medida que esta temperatura decresce. Além disso, foi observada melhor distribuição e diminuição do tamanho das colônias de perlita em relação ao abaixamento da temperatura de último passe.

As temperaturas de último passe nas quais foi possível obter refinamento mais acentuado de grãos ferríticos, a partir de austenita não recristalizada (750 a $840^{\circ} \mathrm{C}$ ) para o aço estudado, são baixas quando comparadas com as temperaturas usuais de laminação (Fig. 5c, d, e, f). Sabe-se, no entanto, que o aumento no teor de Nióbio possibilita o aumento da temperatura de não recristalização, permitindo que sejam empregadas temperaturas mais elevadas de último passe, compatíveis com cargas adequadas ao laminador [15].

O tamanho de grão ferrítico médio diminuiu com a queda da temperatura de aplicação de deformação de acabamento. Os valores obtidos estão representados na Figura 6, onde o tamanho de grão em $\mu \mathrm{m}$ é relacionado com a temperatura de ultima deformação.

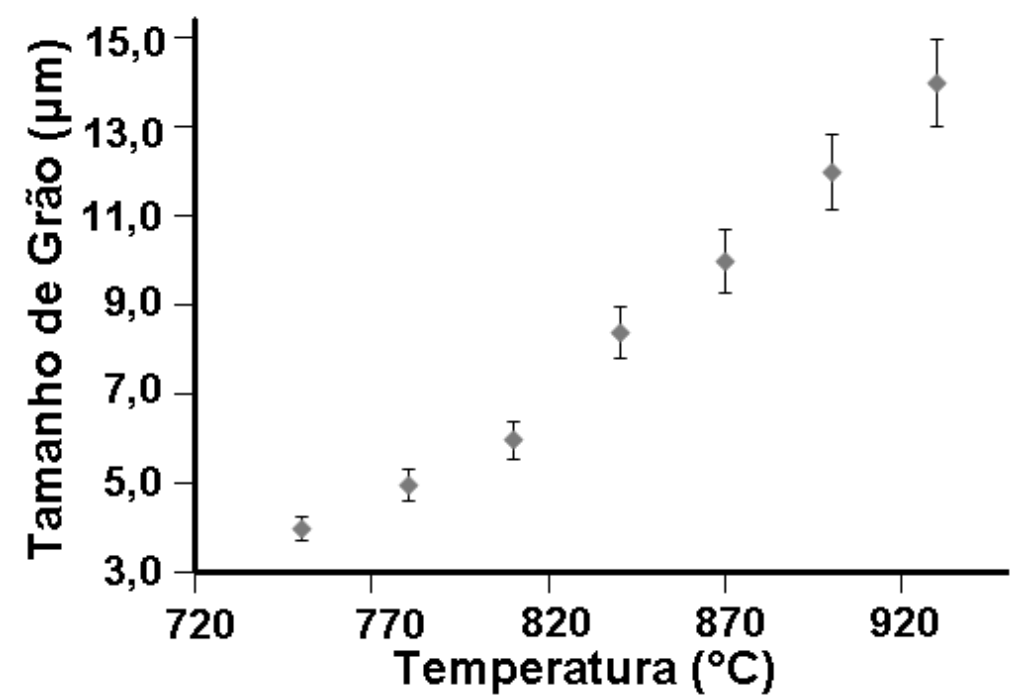

Figura 6. Influência da temperatura de último passe de acabamento no tamanho de grão ferrítico.

Os valores de microdureza obtidos estão listados na Tabela 5 e foram relacionados com as temperaturas do ensaio de torção. Observou-se que a dureza aumenta na medida em que a temperatura de deformação de acabamento diminui.

Tabela 5. Valores obtidos nos ensaios de microdureza em relação às temperaturas da torção e o inverso da raiz quadrada do tamanho de grão.

\begin{tabular}{ccc}
\hline Temperaturas & Dureza (carga 300g) & $\mathrm{d}(\mu \mathrm{m})$ \\
\hline 750 & $175 \pm 6,2$ & 4,0 \\
\hline 780 & $170 \pm 0,5$ & 5,0 \\
\hline 810 & $168 \pm 3,3$ & 6,0 \\
\hline 840 & $167 \pm 2,9$ & 8,4 \\
\hline 870 & $163 \pm 6,9$ & 10,0 \\
\hline 900 & $162 \pm 2,5$ & 12,0 \\
\hline 930 & $161 \pm 7,0$ & 14,0 \\
\hline
\end{tabular}

\footnotetext{
* Contribuição técnica ao $69^{\circ}$ Congresso Anual da ABM - Internacional e ao 14ํㅡㄹ ENEMET - Encontro Nacional de Estudantes de Engenharia Metalúrgica, de Materiais e de Minas, 21 a 25 de julho de 2014, São Paulo, SP, Brasil.
} 


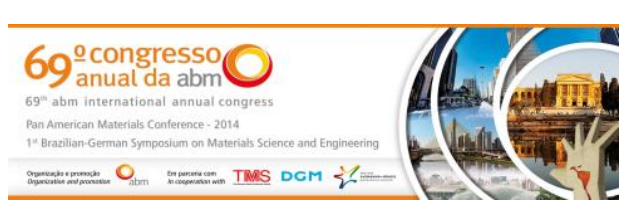

As Figuras 7(a) e 7(b) mostram respectivamente gráficos relacionando a dureza em função das temperaturas dos ensaios e do tamanho de grão.

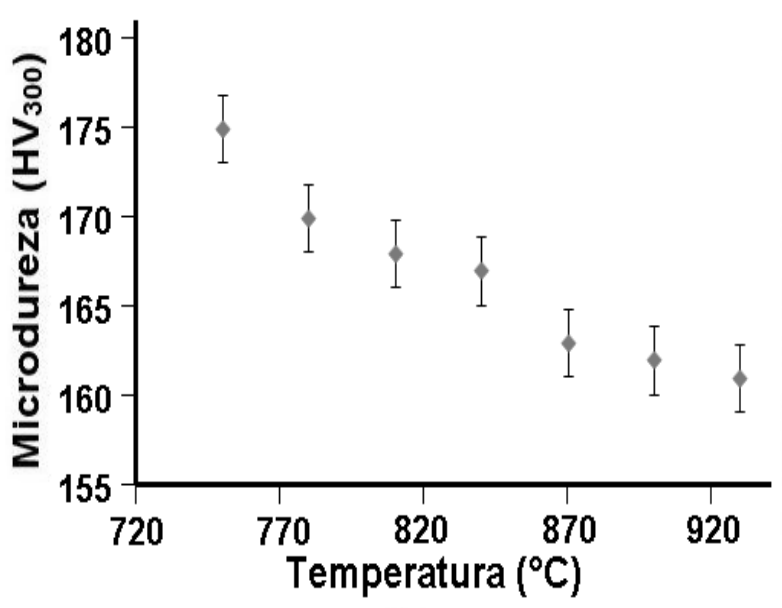

(a)

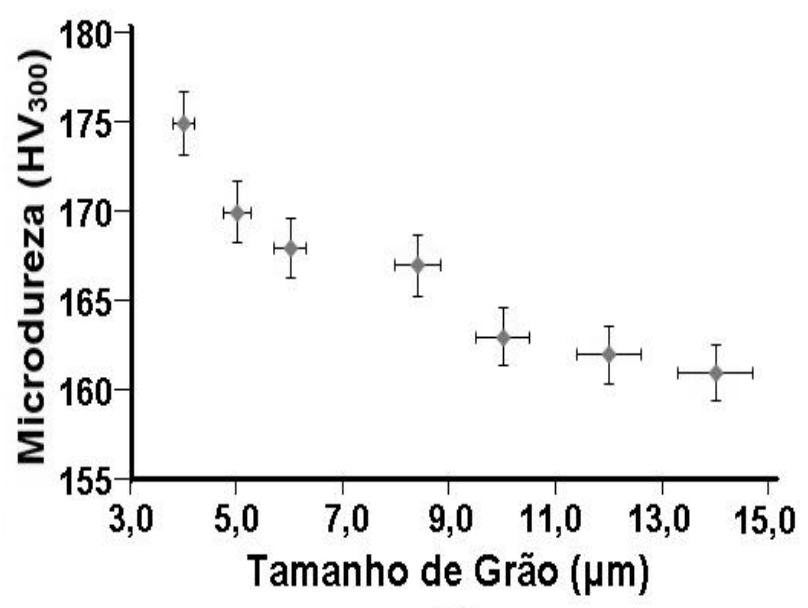

(b)

Figura 7. Gráfico da (a) microdureza em função da temperatura de realização dos ensaios de torção e (b) relação entre a microdureza e o tamanho de grão.

Observa-se que a microdureza é inversamente proporcional ao diâmetro médio de grão, ou seja, quanto menor o tamanho de grão obtido, maior foi o valor da microdureza.

\section{CONCLUSÃo}

As temperaturas críticas determinadas por ensaios de torção a quente para o aço microligado ao Nióbio contendo $0,022 \% \mathrm{Nb}$ foram de $950^{\circ} \mathrm{C}$ para $\mathrm{Tnr}$ e $780^{\circ} \mathrm{C}$ para Ar3. Estes valores estão em acordo com aqueles obtidos utilizando-se equações disponíveis na literatura.

O tamanho de grão ferrítico foi refinado de $14 \mu \mathrm{m}$ para simulações de laminação de acabamento, na região de recristalização, para até $4 \mu \mathrm{m}$ nas simulações na região de não recristalização, como consequência da laminação controlada e a utilização do $\mathrm{Nb}$ como microligante.

As temperaturas de último passe nas quais foi possível obter refinamento de grãos ferríticos a partir de austenita não recristalizada para o aço estudado são baixas, na faixa 750 a $840^{\circ} \mathrm{C}$, quando comparadas com as temperaturas usuais de laminação a quente. A elevação do teor de $\mathrm{Nb}$ do aço permitiria o aumento da temperatura de não recristalização, possibilitando o emprego de temperaturas mais elevadas de último passe, compatíveis com cargas adequadas ao laminador.

Os resultados deste trabalho servem de base para definição dos parâmetros de laminação a quente do microligado ao Nb, em laminador do tipo Steckel.

\section{Agradecimentos}

Os autores agradecem à Companhia Brasileira de Mineração e Metalurgia-CBMM pelo apoio financeiro e discussões e à Gerdau Ouro Branco pelo apoio técnico e fornecimento de amostras.

\footnotetext{
* Contribuição técnica ao $69^{\circ}$ Congresso Anual da ABM - Internacional e ao 14ํㅡㄹ ENEMET - Encontro Nacional de Estudantes de Engenharia Metalúrgica, de Materiais e de Minas, 21 a 25 de julho de 2014, São Paulo, SP, Brasil.
} 


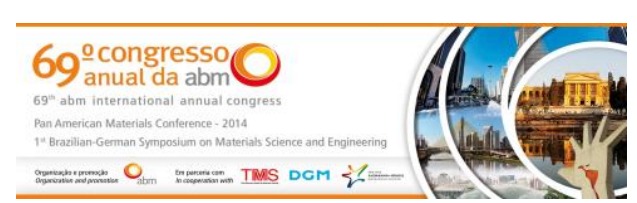

\section{REFERÊNCIAS}

1 Dae-Bum $\mathrm{P}$, Moo-Young H; Jae-Hyeok S, Jin-Yoo S, Kyu-Ho L, Woo-Sang J.

Strengthening Mechanism of Hot Rolled Ti and Nb Microalloyed HSLA Steels Containing Mo and W with Various Coiling Temperature. Materials Science \& Engineering A. 2013;560:528-534.

2 Silva MC. Determinação Experimental da Tenacidade à Fratura da Zona Termicamente Afetada de Junta Soldada de Aço API 5L X80. São Paulo: Escola Politécnica da Universidade de São Paulo; 2009.

3 Gorni, AA. Análise de Processos da Gerência de Suporte Técnico da Laminação a Quente da Companhia Siderúrgica Paulista - COSIPA. In: Congresso de Corte e Conformação de Metais; 2009; São Paulo, Brasil.

4 Turazi A. Estudo de Diferentes Rotas de Processamento para Refino de Grão e Seu Efeito na Estampabilidade de Aços ARBL. Florianópolis: Universidade Federal de Santa Catarina; 2008.

5 Júnior WS. Caracterização e Modelagem Matemática da Fração Recristalizada de Ferrita no Aço Inoxidável Ferrítico AISI 430 Durante o Processo de Deformação a Quente em Laminador Steckel. Belo Horizonte: Universidade Federal de Minas Gerais; 2007.

6 Borato F, Barbosa R, Yue S, Jonas JJ. Effect of Chemical Composition on the Critical Temperature of Microalloyed Steels. ISIJ International. 1988;1:383-390.

7 Ouchi C, Sampei T, Kozasu I. The Effect of Hot Rolling Condition and Chemical Composition on the Onset Temperature of $y-\alpha$ Transformation After Hot Rolling. Transactions of the Iron and Steel Institute of Japan. 1982;22:214-222.

8 Souza SA. Ensaios Mecânicos de Materiais Metálicos-Fundamentos Teóricos e Práticos. São Paulo: Edgard Blucher; 1982.

9 Souza RA, Marques A, Tasca MRB, Nogueira L, Machado MLP. Avaliação da recristalização dinâmica do aço estrutural SAE 4140 através de ensaios de torção a quente. In:II Workshop de Ciência e Tecnologia em Engenharia Metalúrgica e de Materiais; 2012; Vitória. PROPEMM-IFES; 2012.

10 Rosa LB. Estudo do Comportamento Termomecânico do Aço API 5 L Microligado ao NbV-Ti por Ensaios de Torção a Quente. Vitória: Instituto Federal de Educação, Ciência e Tecnologia do Espirito Santo; 2011.

11 Boratto F, Yue S, Jonas JJ, Lawrence T. Projeto de Esquemas de Laminação Controlada Através de Ensaio de Torção Computadorizado. In: COLAM-ABM, 1987, São Paulo, Brasil.

12 Padilha AF, Siciliano Jr F. Encruamento, recristalização, crescimento de grão e textura. São Paulo: ABM; 2005.

13 Barbosa RANM, Boratto FJM, Santos DB. Fundamentos da laminação controlada. Belo Horizonte: UFMG; 1989.

14 Barcelos VM, Vieira EA, Oliveira NJL, De Machado MLP. Análise do Comportamento Mecânico de um Aço Estrutural Através de Ensaios de Torção. REM: R. Esc. Minas. 2013;66(3):317-322.

15 Calvo J, Collins L, Yue S. Design of Microalloyed Steel Hot Rolling Schedules by Torsion Testing: Average Schedule VS. Real Schedule. ISIJ International. 2010;50(8):1193-99.

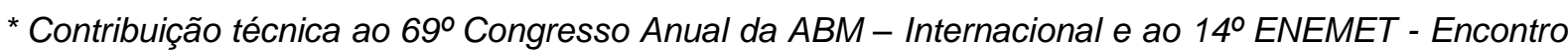
Nacional de Estudantes de Engenharia Metalúrgica, de Materiais e de Minas, 21 a 25 de julho de 2014, São Paulo, SP, Brasil.
} 